addressed by improvements in international communication and development of internationally agreed standards such as the 2004 joint ATS/ERS guidelines on COPD. ${ }^{16}$ All these factors suggest that, with care, comparisons in COPD mortality between countries can be made with increasing confidence. Interpretations of mortality data can be aided by authoritative prevalence surveys using standardised methodology with careful quality control, such as those currently being conducted as part of the Burden of Obstructive Lung Disease (BOLD) project. ${ }^{17}$

So what can one make of the paper by Fuhrman et al in light of the information presented above? Fuhrman et al provide a detailed analysis from which three findings can be highlighted:

- COPD mortality rates in France from 1979 to 1999 decreased slightly in men but rose steadily in women, but rates for both sexes remain substantially lower than in the USA or the UK. These trends are in line with expectations given previous tobacco use trends and with prevalence surveys.

- The ratio of deaths in France with any mention of COPD on the death certificate to deaths with COPD as the underlying cause was 2.1 in 2000-2, which compares with 2.3 in the $\mathrm{USA}^{10}$ and 1.7 in England and Wales. ${ }^{11}$ The main cause for these differences is likely to be the extent to which doctors fill in contributory causes of death on the death certificate. ${ }^{11}$ This suggests that, while multiple cause coding can improve appreciation of the burden of the disease, comparison of such analyses between countries remains problematic.
- There was a substantial discontinuity in death rates following the change from ICD-9 to ICD-10 coding referred to at the beginning of this article. The extent of the fall depended on the specific code used rather than being more uniform across all deaths coded to COPD codes-further suggesting that the fall was likely to be largely artefactual. The authors investigated the fate of the "missing" 5000 or more deaths and suggested that this may have involved the use of the term "chronic respiratory failure"; under ICD-9 coding in France this was coded to COPD codes but was coded elsewhere in the respiratory chapter following the change to ICD10. This change can only be part of the answer as the analyses by Fuhrman et al show that, when comparing COPD with chronic respiratory failure as associated causes of death, the pattern for the underlying causes of death was different.

Fuhrman et $a^{3}$ clearly show that mortality data need careful interpretation but, given this, they can yield useful information. While not perfect-and no data source is-the substantial advances in understanding of such data in recent years and the trend towards harmonisation in clinical practice suggest that such data can be useful for broad scale understanding of the burden of COPD.

Thorax 2006;61:923-924.

doi: $10.1136 /$ thx.2006.065573

Correspondence to: $\operatorname{Dr}$ A L Hansell, Wellcome Intermediate Clinical Fellow, Department of Epidemiology and Public Health, Imperial College London (St Mary's Campus), London W2 IPG, UK; a.hansell@imperial.ac.uk

Competing interests: none.

\section{REFERENCES}

1 Murray CJL, Lopez AD. The Global Burden of Disease. Boston: Harvard University Press, 1996.

2 Murray CJL, Lopez AD. Alternative projections of mortality and disability by cause 1990-2020: Global Burden of Disease Study. Lancet 1997;349:1498-504.

3 Fuhrman C, Jougla E, Nicolau J, et al. Deaths from chronic obstructive pulmonary disease in France, 1979-2002: a multiple cause analysis. Thorax 2006;61:930-45.

4 Mannino DM, Homa DM, Akinbami $\sqcup$, et al. Chronic obstructive pulmonary disease surveillance-United States, 1971-2000. MMWR 2002;51(SS-6): 1-16.

5 Brock A, Griffiths C, Rooney C. The impact of introducing respiratory mortality trends in England and Wales. Health Stat Q 2006:29:9-17.

6 Hansell AL, Bottle RA, Shurlock L, et al. Accessing and using hospital activity data. J Public Health Med 2001;23:51-6.

7 Department of Health. Improving care for patients with chronic obstructive pulmonary disease, Publication No.2006/0241.http:// www.dh.gov.uk/PublicationsAndStatistics/ PressReleases/PressReleasesNotices $/ \mathrm{f}_{\mathrm{s}} /$ en?CONTENT_ID $=4136685 \& \mathrm{chk}=\mathrm{n} / \mathrm{s} 3 \mathrm{JW}$ (accessed 28 June 2006)

8 Williams JG, Mann RY. Hospital episode statistics: time for clinicians to get involved? Clin Med 2002;2:34-7.

9 Bottle A, Hansell A, Aylin P. Hospital episode statistics: time for clinicians to get involved (letter)? Clin Med 2002;2:483-4.

10 Mannino DM, Brown C, Giovino GA. Obstructive lung disease deaths in the United States from 1979 through 1993. Am J Respir Crit Care Med 1997; 156:814-8

11 Hansell AL, Walk JA, Soriano JB. What do COPD patients die from? A multiple cause coding analysis for England \& Wales. Eur Respir 2003;22:809-14.

12 Reid DD, Fletcher CM. International studies in chronic respiratory disease. $\mathrm{Br}$ Med Bull 1971:27:59-64.

13 Seaton A. The new prescription: industrial injuries benefits for smokers. Thorax 1998;53:335-6.

14 Thom TJ. International comparisons in COPD mortality. Am Rev Respir Dis 1989;140:S27-34.

15 Lopez AD, Mathers CD, Ezzati M, et al. Global and regional burden of disease and risk factors, 2001: systematic analysis of population health data. Lancet 2006;367:1747-57.

16 Celli BR, MacNee W, and Committee Members. Standards for the diagnosis and treatment of patients with COPD: a summary of the ATS/ERS position paper. Eur Respir J 2004;23:932-46.

17 Buist AS, Vollmer WM, Sullivan SD, et al. The burden of obstructive lung disease initiative (BOLD): rationale and design. J COPD 2005;2:277-83.

\title{
"Susceptible" smokers?
}

\section{N R Anthonisen}

\section{Many smokers may be "susceptible" to COPD if they live long enough}

th n this issue of Thorax Lokke et al report the incidence of COPD in the Copenhagen City Heart Study. ${ }^{1}$ They were able to do so because they followed a large cohort of representative citizens of
Copenhagen for 25 years with spirometric tests, far longer than any previous such study. Non-asthmatics aged 3060 years with normal initial spirometric parameters and good smoking histories were studied. About 2500 of them underwent spirometric tests at least twice ( 25 years apart), and vital status was ascertained in another 5500 who did not undergo comparable spirometric measurements. COPD was assessed in terms of the current standards for spirometry ${ }^{2}$ staged according to GOLD.

More than $24 \%$ of the continuous smokers who underwent spirometric tests had COPD (defined as $\mathrm{FEV}_{1}<80 \%$ of predicted, $\mathrm{FEV}_{1} / \mathrm{FVC}<70 \%$ ) after 25 years, in stark contrast to never smokers in whom COPD occurred in $<5 \%$. Those who stopped smoking before or during the study did better than those who continued to smoke, and the earlier the cessation occurred, 
the better the outlook; cessation $<10$ years before the end of the study did not appear to help. Sex was not a significant risk factor for COPD (most of the subjects who performed spirometric tests were women), but age at entry to the study was, presumably because older smokers had a history of more pack years at entry than younger smokers.

The authors emphasise that the incidence of COPD was unexpectedly high; it must have been over $25 \%$, given that only $48 \%$ of those alive at 25 years underwent spirometric tests, and those who did not were almost certainly in worse health than those who did. Furthermore, 109 participants (more than $1 \%$ of the total) died of COPD during the observation period and were therefore unavailable for testing. This is distinctly higher than the commonly quoted figure of $15 \%$-that is, $15 \%$ of smokers develop symptomatic COPD, a point recently emphasised by another editorial comment. ${ }^{3}$

The estimate of $15 \%$ of smokers developing COPD is usually attributed to Fletcher et al $^{4}$ whose work forms the basis of most of our current understanding of the disease. I am unable to locate an unequivocal statement in their book quoting this number, but I believe that there are some circumstances that might explain a difference between the purported views of Fletcher and the findings of the Copenhagen City Heart Study. Firstly, most of the COPD in the latter study was "moderate" - that is, the participants had $\mathrm{FEV}_{1}$ values of 50 $79 \%$ of the predicted normal-so it is likely that many of these were not very symptomatic. Secondly, COPD in the early to mid 1960s was somewhat different from today; in my experience, deaths and hospital admissions caused by COPD were not uncommon in men aged 55-65, which is not the case today. If one imagines the rate of loss of $\mathrm{FEV}_{1}$ necessary to culminate in values of 0.5 $1.0 \mathrm{l}$ at the age of 55, assuming the subject started smoking in late adolescence, the result is spectacular and rare today. This is a somewhat long winded way of saying that the COPD "sensitivity" of the Copenhagen Heart Study was very likely considerably greater than that of Fletcher et al.

Lokke et al emphasise that the high incidence of COPD which they observed was due to the length of their study. The mean age at study entry was about 45 years and, given a 25 year follow up period, many of their participants must have been over 70 . The message is that many smokers develop airways obstruction if they live long enough and continue to smoke, and that the number that do so is increasing because of a decline in competing mortality. I heartily agree with this conclusion. If a smoker has an $\mathrm{FEV}_{1}$ of $4.0 \mathrm{l}$ at the age of 30 , his $\mathrm{FEV}_{1}$ will have to decline by about $120 \mathrm{ml} /$ year to develop respiratory failure $\left(\mathrm{FEV}_{1}=1.0 \mathrm{l}\right)$ at the age of 55 , which is uncommon. On the other hand, if the $\mathrm{FEV}_{1}$ declines at a rate of $60 \mathrm{ml} /$ year - the rate of decline of an "average" smoker ${ }^{4}$-respiratory failure is likely to occur at the age of 80 in an "average" smoker. It is not uncommon for smokers to reach 80 years of age nowadays.
An argument can therefore be made that many (perhaps most) smokers are "susceptible" to COPD if they live long enough. Indeed, the definition of susceptibility may need to be examined. Furthermore, the GOLD definition of COPD as an "abnormal" response to inhaled toxins may need revision, or at least a rethink. This is not to say that people's propensity to develop airways obstruction in response to smoking does not vary; approximately $65 \%$ of continuous smokers in the Copenhagen City Heart Study had $\mathrm{FEV}_{1} / \mathrm{FVC}>70 \%$ after 25 years. There are such differences, and it is important-though difficult-to work out their mechanisms.

Thorax 2006;61:924-925.

doi: $10.1136 /$ thx.2006.065623

Correspondence to: $\operatorname{Dr} N$ R Anthonisen University of Manitoba, Respiratory Hospital Winnipeg, Canada R3A 1R8; nanthonisen@ exchange.hsc.mb.ca

Competing interests: none.

\section{REFERENCES}

1 Lokke A, Lange P, Scharling H, et al. Developing COPD: a 25 year follow up study of the general population. Thorax 2006;61:935-9.

2 Celli BR, MacNee W, Agusti A, et al. Standards for the diagnosis and treatment of patients with COPD: a summary of the ATS/ERS position paper. Eur Respir J 2004; 23:932-46.

3 Rennard SI, Vestbo J. The dangerous underestimate of 15\%. Lancet 2006:367:1216-9.

4 Fletcher CM, Peto R, Tinker $C$, et al. The natural history of chronic bronchitis and emphysema. Oxford: Oxford University Press, 1976.

5 Anthonisen NR, Connett JE, Murray RP, for the Lung Health Study Research Group. Smoking and lung function in Lung Health Study participants after 11 years. Am J Respir Crit Care Med 2002;166:675-9.

\section{Genetic variability of the $\beta_{2}$ adrenergic receptor and asthma exacerbations}

\section{S B Liggett}

\section{Predictive value of genetic tests for asthma exacerbations}

T he treatment of asthma remains a formidable task for clinicians, despite the development of new treatment options such as long acting $\beta$ agonists, potent inhaled corticosteroids, and leukotriene receptor antagonists. The complexities in treatment arise not only from temporal changes in the clinical status of patients (such as viral infections and allergy exposures), but also from the well recognised variability between individuals in the response to treatment. This variability is found with the most widely used treatment for asthma-the $\beta$ agonistswhich act to dilate constricted airways by binding to the $\beta_{2}$ adrenoceptor on airway smooth muscle. It has been suggested that up to $50 \%$ of the variability in response to $\beta$ agonists between individuals has a genetic basis. ${ }^{1}$ Beta agonists evoke smooth muscle relaxation in airways that have become constricted from virtually any spasmogen, so it is no wonder they have a central role in treating asthma.

However, several aspects of $\beta_{2}$ adrenoceptor signalling have been lurking in the shadows for many years. Firstly, in virtually every cell type that has been studied, chronic exposure $(\sim 8$ hours or more) to $\beta$ agonists results in a loss of receptor expression with accompanying desensitisation of the cellular response. ${ }^{2}$ At the physiological level, desensitisation could be manifested as tachyphylaxis. Clinically, tachyphylaxis to $\beta$ agonists could lead to a variety of outcomes such as progressive loss of the bronchodilating effect, a loss of the protective effect against bronchoconstriction, and increased exacerbations. It has also been recognised for over 25 years that corticosteroids increase $\beta_{2}$ adrenoceptor expression, ${ }^{3}$ which could mitigate against agonist promoted downregulation. ${ }^{4}$ The clinical response to corticosteroids in asthma may therefore involve both anti-inflammatory effects which reduce local spasmogens, 